\title{
Identification of Methyl-branched Chain Dicarboxylic Acids in Amniotic Fluid and Urine in Propionic and Methylmalonic Acidemia
}

\author{
CORNELIS JAKOBS, LAMBERTUS DORLAND, LAWRENCE SWEETMAN, MARINUS DURAN, \\ WILLIAM L. NYHAN, AND SYBE K. WADMAN \\ Department of Pediatrics, Academic Hospital of the Free University of Amsterdam, Amsterdam, The Netherlands \\ [C.J.], University Children's Hospital "Het Wilhelmina Kinderziekenhuis," Utrecht, The Netherlands \\ [L.D.,M.D.,S.K.W.], and Department of Pediatrics, University of California San Diego, La Jolla,
}

California 92093 [L.S., W.L.N.]

\begin{abstract}
Methyladipic, 4-methylpimelic, 4-methylsuberic, pimelic, and azeleic acids were identified by gas chromatography-mass spectrometry in the amniotic fluid of fetuses with propionic acidemia. These compounds were virtually undetectable in normal amniotic fluid. Concentrations much higher than those of the amniotic fluid were found in the urine of neonatal infants with propionic acidemia and methylmalonic acidemia. It appears that the accumulation of these compounds is a consequence of the accumulation of propionyl-CoA. Evidence was obtained for the presence of other methyl-branched chain dicarboxylic acids. 4-Methylpimelic acid and 4-methylsuberic acid have not previously been identified in human physiological fluids. (Pediatr Res 18:1185-1191, 1984)
\end{abstract}

\section{Abbreviations}

AF, amniotic fluid

GCMS, gas chromatography-mass spectrometry

SIM, selected ion monitoring

CI, chemical ionization

4-MPA, 4-methylpimelic acid

4-MSuA, 4-methylsuberic acid

EI, electron impact

AzA, azeleic acid

The dicarboxylic acids of the AF and the urine have been investigated in propionic acidemia and methylmalonic acidemia using GCMS in the SIM mode with ammonia CI (10). Two compounds were detected which were distinctly elevated in the AF of fetuses affected with propionic acidemia. These compounds were absent or present in only small amounts of normal AF. A small elevation was found in the AF samples of fetuses with methylmalonic acidemia. The purpose of this report is to describe the identification of these compounds as 4-MPA and 4MSuA. We also identified these compounds in the urine of patients with propionic acidemia and methylmalonic acidemia. In each instance, the concentrations obtained in neonatal urine

September 22, 1983; accepted March 13, 1984

Requests for reprints should be addressed to Department of Pediatrics, Academic Hospital of the Free University of Amsterdam, De Boelelaan 1117, $1007 \mathrm{MB}$ Amsterdam, The Netherlands.

This work was supported by United States Public Health Service Grant HD04608 from the National Institute of Child Health and Human Development and Grants GM 27583 and GM 17702 from the National Institute of General Medical Science, National Institutes of Health, Bethesda, MD. were considerably greater than in AF. Evidence was obtained for the presence of a number of other methyl-branched dicarboxylic acids. 4-MPA and 4-MSuA have not previously been identified in body fluids.

\section{MATERIALS AND METHODS}

Normal AF samples were obtained between 16 and 18 weeks of pregnancy by amniocentesis and stored at $-20^{\circ} \mathrm{C}$. Amniotic fluids from pregnancies at risk were sent for analysis as sterile fluids or frozen on dry ice and stored prior to analysis at $-20^{\circ} \mathrm{C}$. Amniotic fluid samples were available for four patients with propionic acidemia and two patients with methylmalonic acidemia previously diagnosed in the laboratory by stable isotope dilution analysis for methylcitric acid and methylmalonic acid in the AF (16). Urine samples were collected on the 3rd and the 28 th days of life from a patient with propionic acidemia. She had been diagnosed prenatally by the detection of methylcitric acid in the amniotic fluid, and propionyl-CoA carboxylase deficiency was documented in cultured fibroblasts obtained postnatally (2). Urine samples were collected on the 2 nd and the 21 st days of life from the patient with methylmalonic acidemia. She too had been diagnosed prenatally and belonged to the $m u t$ complementation group. She was $\mathrm{B}_{12}$ unresponsive.

Liquid partition chromatography GCMS procedure. One to 4 $\mathrm{ml}$ of AF were studied. Urine samples (2-6 ml, depending on creatinine content) were prepared and analyzed in the same way as the AF samples. The analytical procedure consisted of liquid partition chromatographic prefractionation, formation of trimethylsilyl derivatives, and ammonia CI GCMS in the SIM mode as previously described (10). The internal standard was 2hydroxy- $n$-caproic acid. Its protonated molecular ion with $\mathrm{m} / z$ 277 was selected for monitoring. On this SIM trace also glutaric acid was monitored. The ions at $\mathrm{m} / z$ 291, 319, and 347 were monitored to assess the presence of adipic acid, suberic acid, and sebacic acid, respectively. The ions at $\mathrm{m} / \mathrm{z} 305,333$, and 361 were monitored in a second GCMS analysis to assess the presence of $\mathrm{C}_{7}-\mathrm{C}_{9}$ - and $\mathrm{C}_{11}$-dicarboxylic acids.

The GC column was $3 \% \mathrm{OV}-17$ and the GC temperature was $100^{\circ} \mathrm{C}$ isothermal for $4 \mathrm{~min}$ and then programmed at $8^{\circ} / \mathrm{min}$ to $250^{\circ} \mathrm{C}$. To perform SIM, the selected ions were repetitively scanned using a $100-$ msec dwell time at each $\mathrm{m} / \mathrm{z}$. Areas of the SIM peaks were integrated by the computer following operator selection of the baseline points.

Synthesis of methylpimelic and methylsuberic acids. The monomethyl ester of succinic acid was from Fluka, Buchs, Switzerland, and the monomethyl ester of adipic acid was obtained from Aldrich Europe, Beerse, Belgium. The monomethyl esters of methylmalonic acid, glutaric acid, 2-methylglutaric acid, 3-meth- 
ylglutaric acid, and pimelic acid were prepared according to Furniss et al. (5).

2-, 3-, and 4-methylpimelic acids were prepared by anodic coupling (the Kolbe reaction) (6) of the monomethyl esters of methylmalonic acid and adipic acid, 3-methylglutaric acid and succinic acid, and 2-methylglutaric acid and succinic acid, respectively. 2-, 3-, and 4-methylsuberic acids were prepared by anodic coupling (6) of the monomethyl esters of methylmalonic acid and pimelic acid, 3-methylglutaric acid and glutaric acid, 2methylglutaric acid and glutaric acid, respectively. Free acids were obtained by alkaline hydrolysis of the Kolbe reaction mixtures. After acidification to $\mathrm{pH} 1$, the dicarboxylic acids were extracted with ethyl acetate and trimethylsilylated with $\mathrm{N}, \mathrm{O}$ bis(trimethylsilyl) acetamide in chloroform for investigation by GCMS.

Identification of unknown compounds. For the identification of unknown urinary compounds and comparison of gas chro- matographic and mass spectrometric characteristics of these compounds with those of the authentic 2-, 3-, and 4-methylpimelic and 2-, 3-, and 4-methylsuberic acids, the urine (collected on the 2 nd day of life) from a European neonate with propionic acidemia (not further included in tables and figures) was used, because the original materials were no longer available. Cochromatography with the authentic compounds was done on a packed SE52 column and GCMS analyses were performed on a CP Sil 5 capillary column (Chrompack, Middelburg, The Netherlands).

\section{RESULTS}

A typical ammonia CI GCMS chromatogram of a normal AF sample is shown in Figure 1 and the chromatogram for an AF sample from a pregnancy in which the fetus was affected with propionic acidemia shown in Figure 2. Peak A at $m / z 319$ while barely detectable in normal AF was highly elevated in the sample

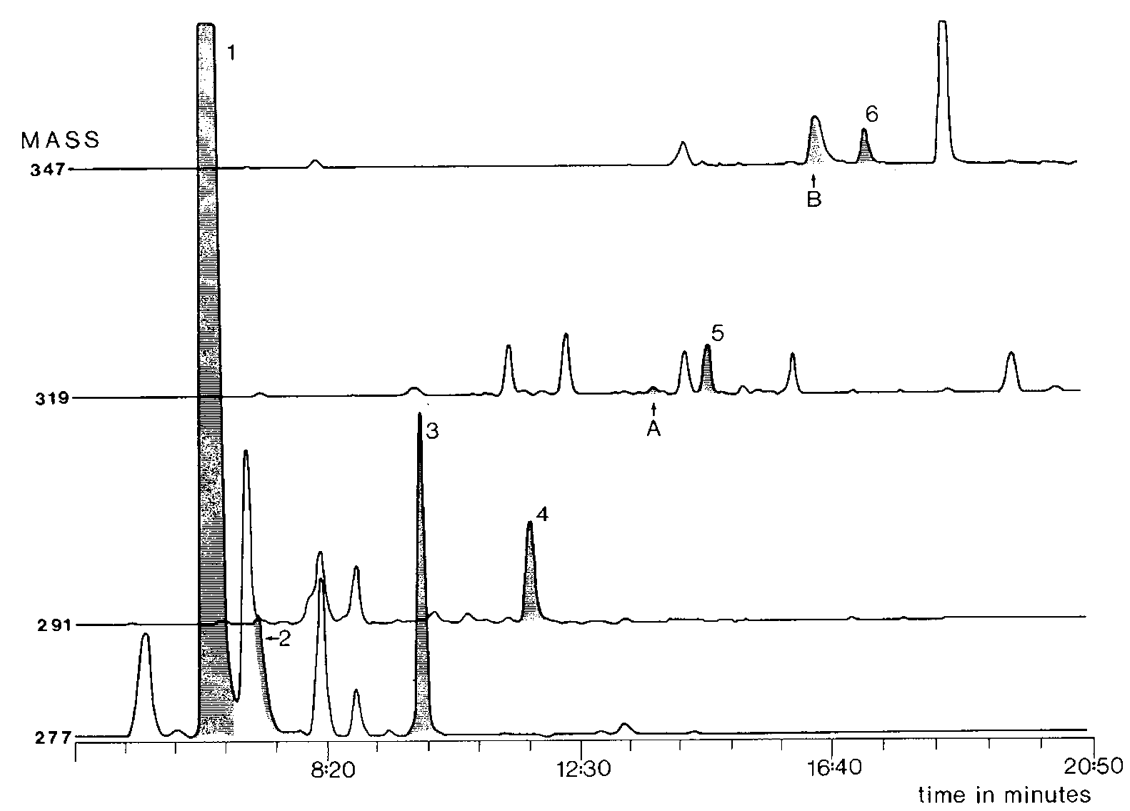

Fig. 1. CI SIM chromatograms of normal amniotic fluid, monitored at $m / z 277,291,319$, and 347. The numbered compounds are: 1 , 2hydroxy- $n$-caproic acid, the internal standard; 2 , ethylmalonic acid; 3 , glutaric acid; 4 , adipic acid; 5 , suberic acid; 6 , sebacic acid.

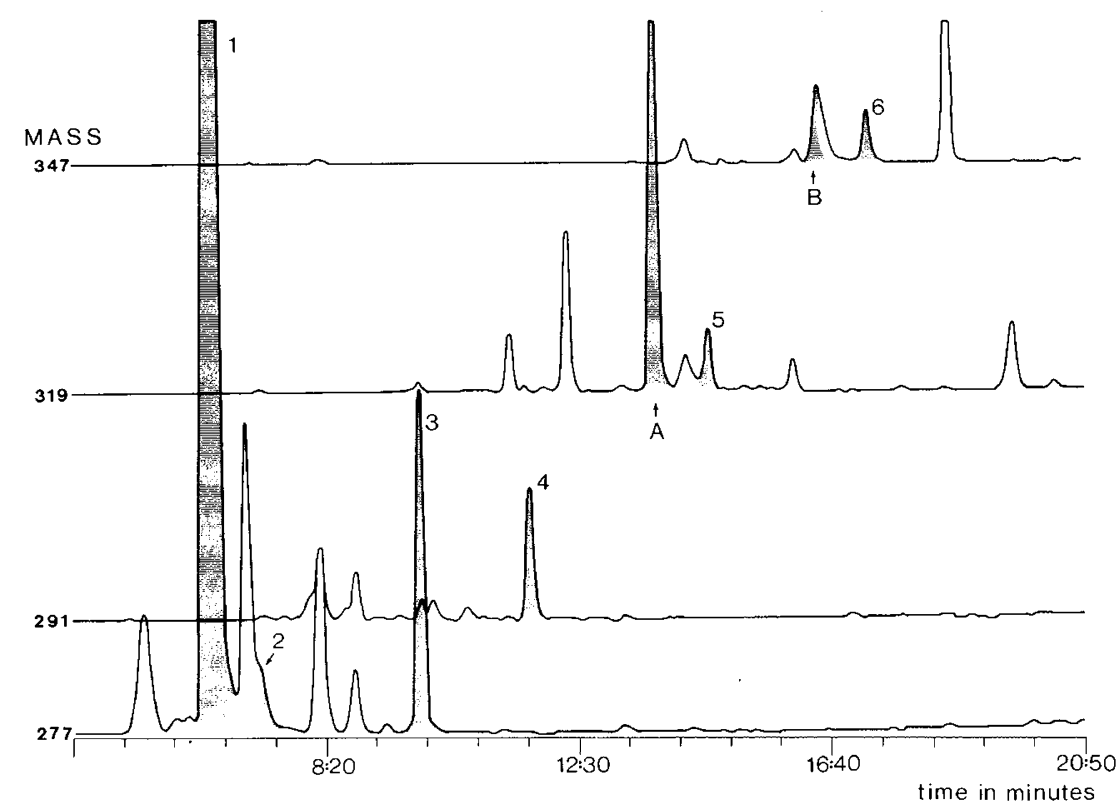

Fig. 2. CI SIM chromatograms of amniotic fluid of a fetus with propionic acidemia, monitored at $m / z 277,291,319$, and 347 . The numbered compounds are the same as in Figure 1. Peaks $A$ and $B$ represent compounds to be identified. Peak A has been identified as 4-methylpimelic acid. Peak B remains not definitely identified, but it appears to be methylazeleic acid. 
from the fetus with propionic acidemia. Peak B detected at $m / z$ 347 was greater in the patient with propionic acidemia. In Figure 3 , the CI SIM chromatogram is depicted of the analysis of the urine obtained on the 3rd day of life from an infant with propionic acidemia. There was a prominent peak A at $\mathrm{m} / z 319$ as was observed in the amniotic fluid chromatogram. Peak B was also distinctly elevated in the urine chromatogram. There were also considerable elevations in the excretions of glutaric acid, adipic acid, suberic acid, and sebacic acid.

EI GCMS of a 10-ml sample of AF from the fetus with propionic acidemia and of the urine shown in Figure 3 produced a mass spectrum (Fig. 4, top) for a peak $\mathrm{A}$ in which the highest $\mathrm{m} / \mathrm{z}$ was 303 . This spectrum was similar to the mass spectrum of suberic acid $(3,8,13)$ and suggested the possibility that peak A represented a branched isomer of suberic acid. The retention time and EI-mass spectrum of compound A were compared with those of authentic 2-, 3-, and 4-methylpimelic acid trimethylsilyl derivatives. The latter compounds can be separated completely by GC on a SE52 packed column (retention times, 52.30, 53.23, and $53.90 \mathrm{~min}$, respectively) as well as on a capillary CP Sil 5 column under GCMS conditions. The mass spectrum of 2methylpimelic acid differed considerably from those of 3- and 4methylpimelic acid which differed only slightly. In a urine sample collected from another neonate, a peak was observed with a retention time of $53.81 \mathrm{~min}$. Investigation by gas cochromatography (SE52 column) and GCMS (CP Sil 5 column) revealed the

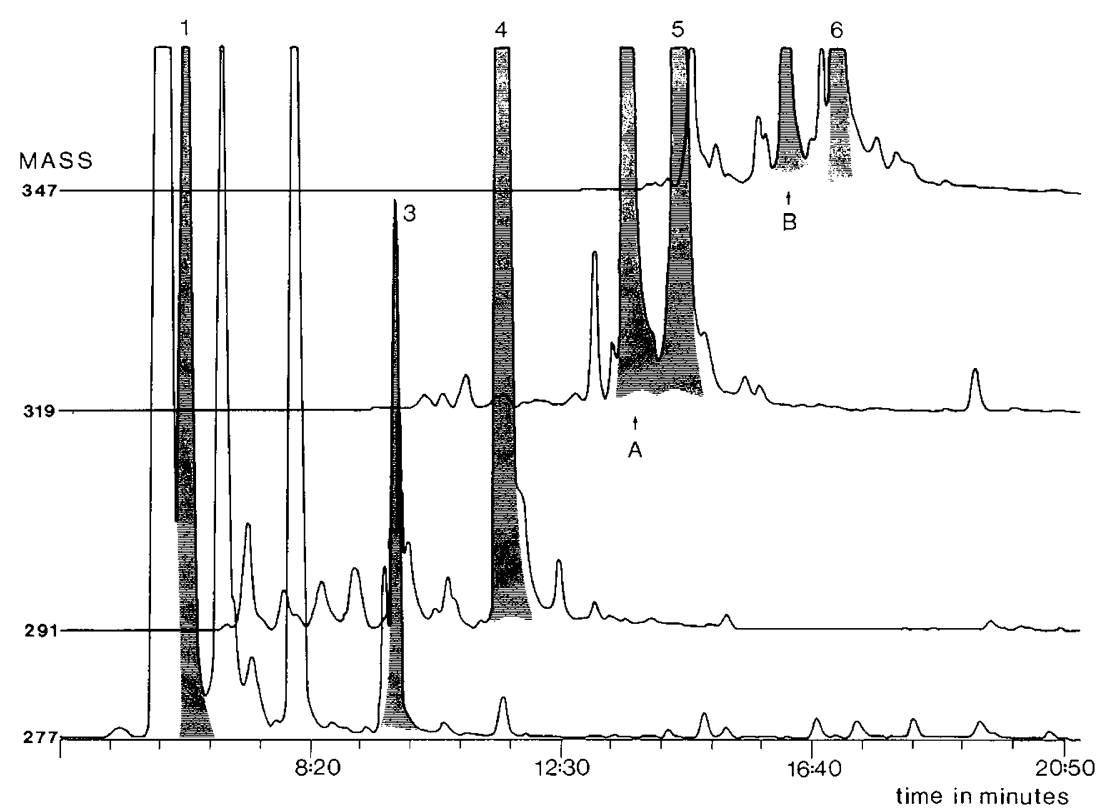

Fig. 3. CI SIM chromatograms of urine obtained on the 3rd day of life from a neonate with propionic acidemia, monitored at $\mathrm{m} / z 277,291$, 319 , and 347.
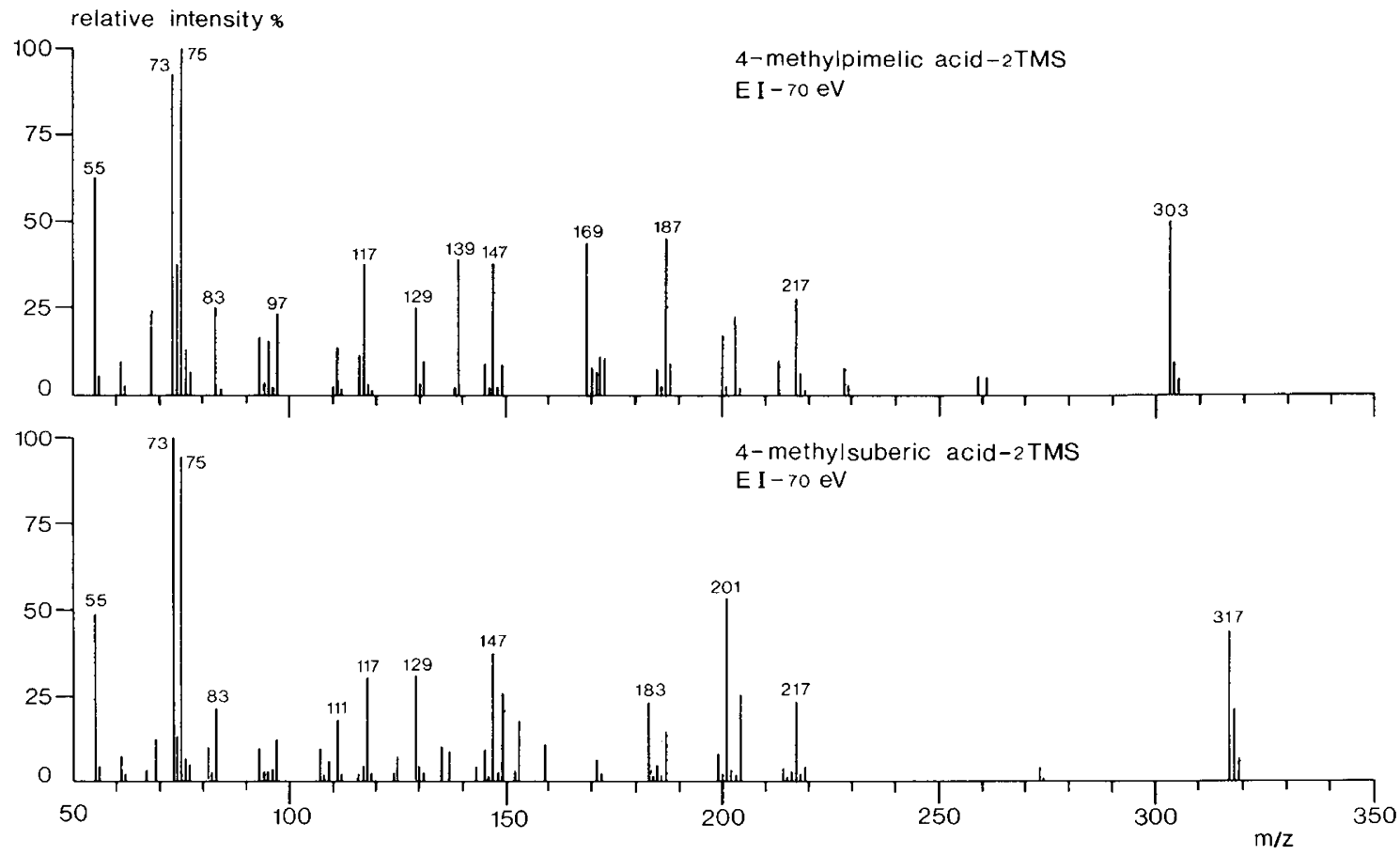

Fig. 4. Top, EI mass spectrum of compound A from the urine of a neonate with propionic acidemia (Fig. 3). Bottom, EI mass spectrum of compound $E$ from the urine of a neonate with propionic acidemia (Fig. 6). 
presence of 4-methylpimelic acid. Compound A had the same chromatographic and mass spectrometric characteristics. Peak A was concluded to be 4-MPA.

Peak B from the urine sample of the patient with propionic acidemia had an EI mass spectrum that was rather similar to that of sebacic acid, but the retention time was shorter. Peak B has not been identified, but this information along with the identification of 4-MPA suggests that it may be another methylbranched chain dicarboxylic acid, presumably methylazeleic acid. In the samples of $\mathrm{AF}$, the shape of the peak suggested the possibility of a coeluting contaminant.

On the basis of these observations it was of interest to examine the samples for the presence of odd-numbered straight chain dicarboxylic acids $\left(\mathrm{C}_{7}-\mathrm{C}_{9^{-}}\right.$and $\mathrm{C}_{11}$-dicarboxylic acids) and methyl-branched chain dicarboxylic acids. For this purpose, we selected the protonated molecular ions at $\mathrm{m} / z$ 305, 333, and 361 .
Figures 5 and 6 depict the CI-SIM chromatograms of samples of $\mathrm{AF}$ from a fetus with propionic acidemia, and urine of the patient with propionic acidemia. Each of six unknown compounds $(C-$ $H$ ) was highly elevated in the urine of the patient with propionic acidemia. In normal AF, only peak $F$ was more than barely detectable and this peak was very small. In the AF of the patient with propionic acidemia There were appreciable amounts of peaks C, E, and F. EI GCMS of the urine sample permitted positive identification of peak $\mathrm{C}$ as 3-methyladipic acid and peak $\mathrm{D}$ as pimelic acid by comparing the mass spectra obtained with those published $(3,8,13)$. The EI-mass spectrum of peak $F$ was identical to that of AzA ( $\mathrm{C}_{9}$-dicarboxylic acid) $(3,13)$.

The mass spectrum of peak $E$ is shown in Figure 4 , bottom. The retention time and EI-mass spectrum of this compound $E$ were compared with those of authentic 2-, 3-, and 4-methylsuberic acid trimethylsilyl derivatives and peak $E$ was identified as

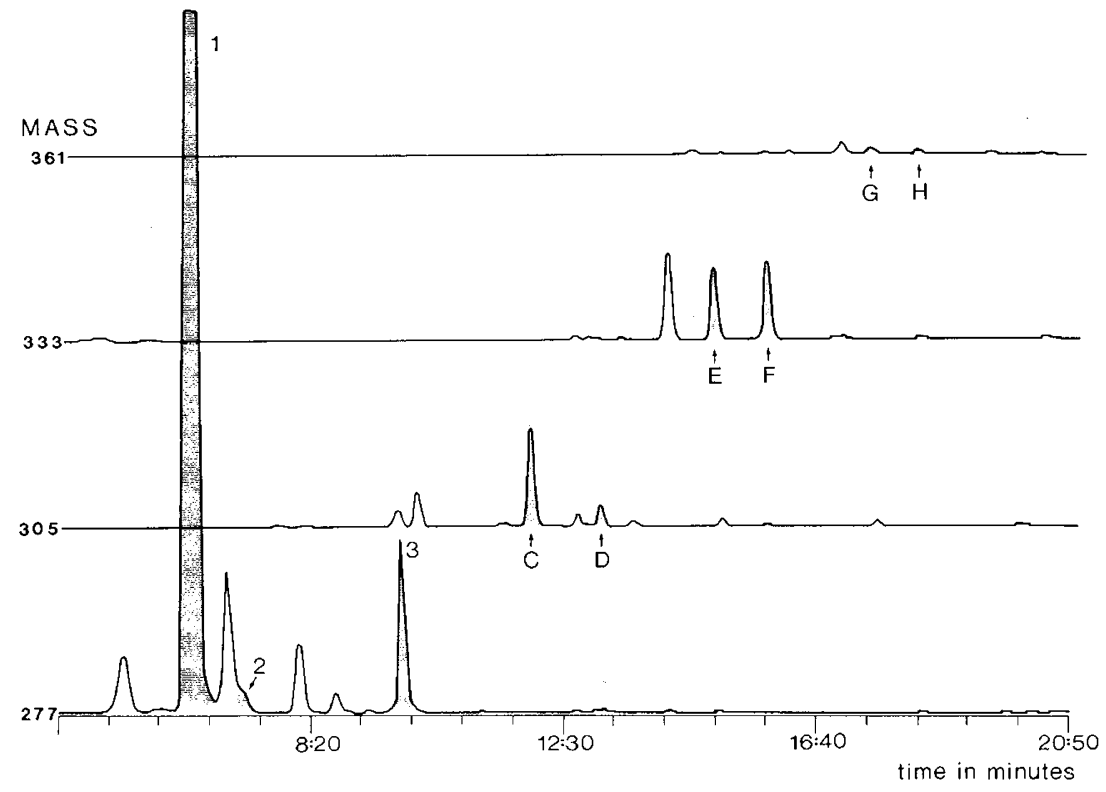

Fig. 5. CI SIM chromatograms of amniotic fluid of a fetus with propionic acidemia, monitored at $m / z 277,305,333$, and 361 . Peaks $C-H$ represent compounds to be identified. They were identified as: $C, 3$-methyladipic acid; $D$, pimelic acid; $E$, 4-methylsuberic acid; $F$, azeleic acid. Peaks $G$ and $H$ are thought to represent methylsebacic acid and undecanedioic acid.

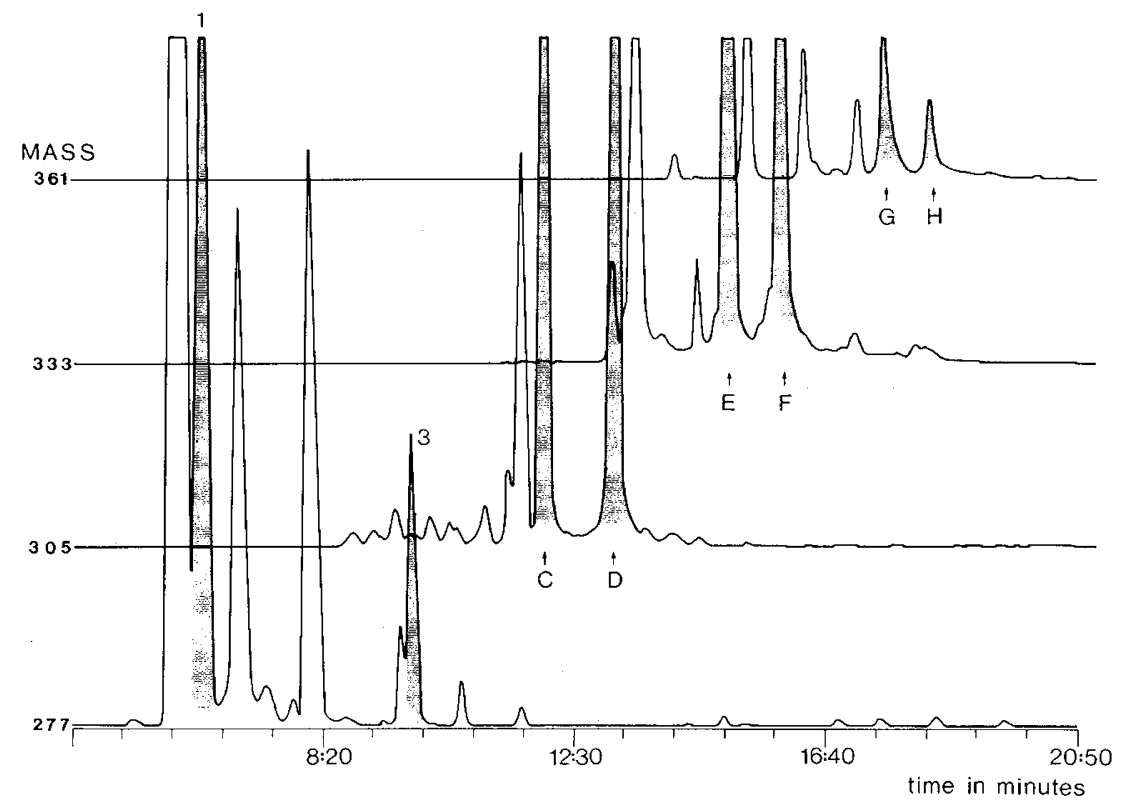

Fig. 6. CI SIM chromatograms of urine on the 3rd day of life from a neonate with propionic acidemia, monitored at $\mathrm{m} / \mathrm{z} 277,305,333$, and 361. 
4-MSuA as in the case of 4-MPA. Both AzA and 4-MSuA were elevated in the amniotic fluid of the fetus with propionic acidemia (Fig. 5).

Peak $\mathrm{G}$ was tentatively identified as methylsebacic acid. Peak $\mathrm{H}$ appeared to be a straight chain $\mathrm{C}_{11}$-dicarboxylic acid, undecanedioic acid (3). In addition there were two compounds with a molecular ion of $m / z 374$, of which the one with the longest retention time had a mass spectrum that resembled authentic $\mathrm{C}_{12}$-dicarboxylic acid. It is possible that the first compound is a methyl-branched- $\mathrm{C}_{11}$-dicarboxylic acid. 4-MPA and 4-MSuA were present in relatively large amounts in the urine of the patient with propionic acidemia (Table 1). On the 3 rd day of life, concentrations were 56 and $38 \mu \mathrm{mol} /$ liter, respectively, and were of the same order of magnitude as the concentrations of the other dicarboxylic acids. The decrease in concentration by the 28th day is consistent with the catabolic nature of the first days of life and the effects of therapy in stabilizing the metabolic state of the infant. A similar pattern was observed in the patient with methylmalonic acidemia in whom the concentrations of 4MPA and 4-MSuA were 26 and $34 \mu \mathrm{mol} /$ liter, respectively, on day 2 and considerably less on day 21 . The change was less striking in the patient with methylmalonic acidemia reflecting a less vigorous approach to therapy. In the AF of fetuses with propionic acidemia (Table 2), 4-MPA ranged from 0.20 to 1.12 $\mu \mathrm{mol} /$ liter while in control amniotic fluid there was essentially none. In two AF samples of patients with methylmalonic acidemia, the level was $0.05 \mu \mathrm{mol} /$ liter. The concentrations of 3methyladipic acid, pimelic acid, and 4-MSuA in the AF of the patients with propionic acidemia were all appreciably greater than in control AF. This was also generally true of AzA but in case 3 the concentration fell within the normal range. Some of these compounds were also slightly elevated in the AF of the patients with methylmalonic acidemia (Table 2) but less strikingly so than in propionic acidemia. Using the criterion of an elevation $3 \mathrm{SD}$ above the normal mean as significant, elevated levels of glutaric acid and adipic acid were found in a number of AF samples. In one (case 1) of four pregnancies in which the fetus had propionic acidemia and in two of two with methylmalonic acidemia, there were significant elevations of glutaric acid. In one each of propionic acidemia and methylmalonic acidemia, there also were elevated concentrations of adipic acid. The 12-fold elevation of the concentration of adipic acid in case 1 with methylmalonic acidemia was verified by a repeat analysis ( 3.86 and $3.78 \mu \mathrm{mol} /$ liter), and the identification of the adipic acid was confirmed by the EI mass spectrum.

\section{DISCUSSION}

4-Methylpimelic acid and 4-methylsuberic acid are newly identified metabolites in mammalian physiology, not previously described in man. These compounds appear to reflect the accumulation of propionyl-CoA, rather than methylmalonyl-CoA because they were found more prominently in propionic acidemia than in methylmalonic acidemia. In each disorder, they were much more prominent in the neonatal urine than in the amniotic fluid and fluctuated in concentration with the age and clinical condition of the patient. The compounds were present in considerable concentration in each of four amniotic fluids bathing fetuses with propionic acidemia while they were virtually undetectable in normal AF. These properties would permit their use in the prenatal diagnosis of propionic acidemia. However, they do not have advantages over the use of methylcitric acid for this purpose and the availability of the stable isotope internal standard of methylcitric acid is a major advantage in prenatal diagnosis (16). 4-MPA and 4-MSuA were also considerably elevated in the AF in methylmalonic acidemia, but much less so than in propionic acidemia.

Another compound not previously identified in AF was 3methyladipic acid. Its concentration in normal AF was higher than those of 4-MPA and 4-MSuA, but lower than those of glutaric acid, adipic acid, suberic acid, and sebacic acid. The variations in concentration of this compound in AF samples of fetuses with propionic acidemia and methylmalonic acidemia paralleled those observed with 4-MPA and 4-MSuA. The same is true for the concentration of 3-methyladipic acid in the urine of the infants with propionic and methylmalonic acidemia. Evidence was obtained for the presence of two more branched-chain dicarboxylic acids, methylazeleic acid and methylsebacic acid in the urine of patients with propionic acidemia and methylmalonic acidemia. The identity of these compounds is less secure, and dimethyl-branched or ethyl-branched dicarboxylic acids cannot be excluded, but in view of the similarities of the mass spectra and the identification of 3-methyladipic acid, 4-MPA, and 4MSuA it is likely that these metabolites are monomethylbranched dicarboxylic acids. The odd-numbered straight chain dicarboxylic acids, pimelic acid and azeleic acid, were found in very low concentrations in normal AF. The concentrations of these compounds in the AF samples of fetuses with propionic acidemia and methylmalonic acidemia tended to be elevated and they were distinctly elevated in neonatal urine. Glutaric acid and adipic acid were moderately elevated in the amniotic fluid of some pregnancies in which the fetuses had propionic or methyl-

Table 1. Concentrations ( $\mu$ mol/liter) of 5-10 carbon dicarboxylic acids in the urine of infants with propionic acidemia and methylmalonic acidemia

\begin{tabular}{|c|c|c|c|c|c|c|}
\hline \multirow[t]{2}{*}{ peak } & \multirow{2}{*}{$\frac{\text { SIM trace }}{\mathrm{m} / \mathrm{z}}$} & \multirow[t]{2}{*}{ identity of acid } & \multicolumn{2}{|c|}{ propionic acidemia } & \multicolumn{2}{|c|}{ methylmalonic acidemia } \\
\hline & & & $3 r d$ day & 28 th day & 2nd day & 21 st day \\
\hline 3 & 277 & glutaric & 5.8 & 1.0 & 6.9 & 8.6 \\
\hline 4 & 291 & adipic & 124 & 3.3 & 106 & 50 \\
\hline $\mathrm{C}$ & 305 & 3-methyladipic & 43 & 2.8 & 30 & 5.4 \\
\hline D & 305 & pimelic & 41 & 8.7 & 54 & 23 \\
\hline A & 319 & 4-methylpimelic & 56 & 0.8 & 26 & 4.9 \\
\hline 5 & 319 & suberic & 58 & 6.4 & 36 & 23 \\
\hline $\mathrm{E}$ & 333 & 4-methylsuberic & 38 & 0.9 & 34 & 11 \\
\hline F & 333 & azeleic & 25 & 4.1 & 19 & 17 \\
\hline 6 & 347 & sebacic & 23 & 0.5 & 2.2 & 1.0 \\
\hline conce & ation of $\mathrm{cr}$ & nine $(\mathrm{g} / \mathrm{l})$ & 0.16 & 0.06 & 0.20 & 0.13 \\
\hline
\end{tabular}


Table 2. Concentrations ( $\mu$ mol/liter) of 5-10 carbon dicarboxylic acids in normal amniotic fluids and amniotic fluid of fetuses with propionic acidemia and methylmalonic acidemia (N.D. signifies not determined)

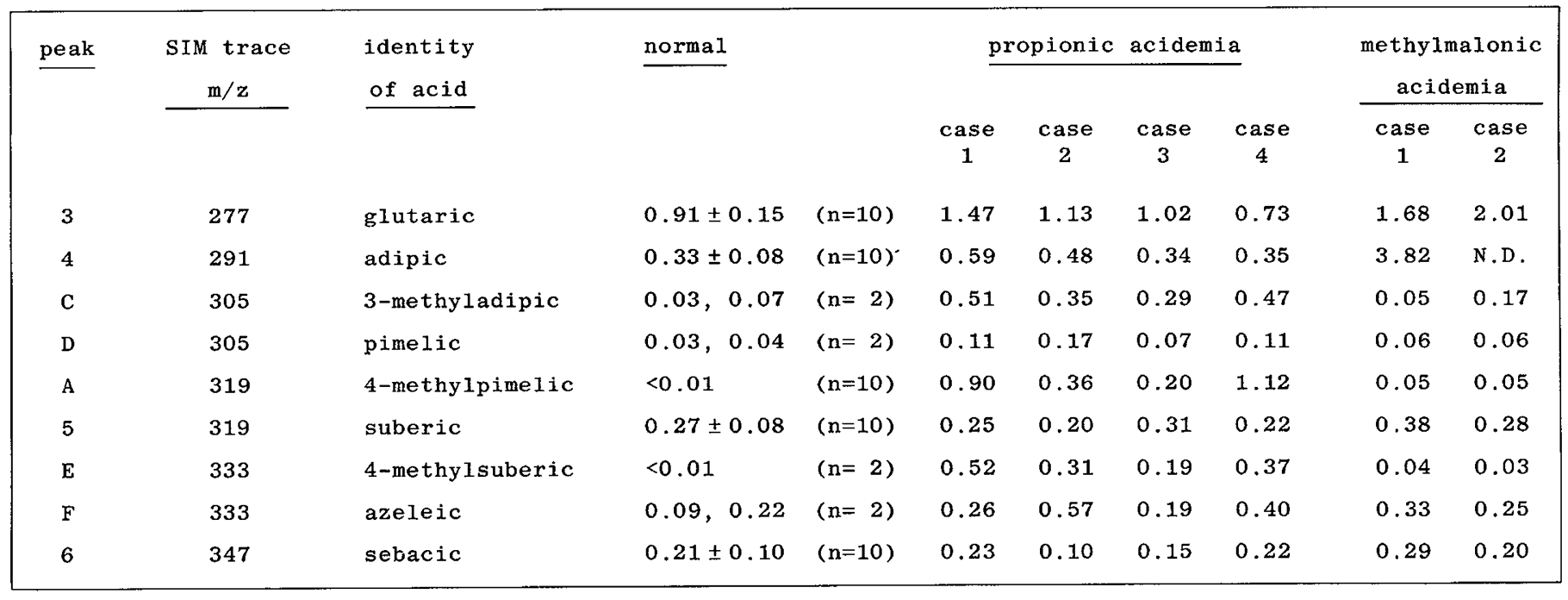

malonic acidemia. Glutaric acid has been noted to be elevated in the urine of some patients with propionic acidemia (4). Adipic acid and other dicarboxylic acids can be elevated in urine due to severe ketosis, but it is unlikely that this is the cause of the elevation of adipic acid in the amniotic fluids as 3-hydroxybutyric acid was normal in these amniotic fluids (11). Patients with propionic acidemia and methylmalonic acidemia may have low levels of plasma carnitine $(1,14)$, presumably as a result of the formation of acylcarnitines by reaction with propionyl-CoA and methylmalonyl-CoA. This should not lead to dicarboxylic aciduria. A number of methyl-branched short chain dicarboxylic acids have been identified in human urine (15). 3-Methyladipic acid, 3-methylpimelic acid, and 3-methylsuberic acid were present in all urine studied. These were assumed to arise from $\omega$ oxidation followed by $\beta$-oxidation of ante-iso or 3-methyl substituted fatty acids of exogenous origin. Pettersen and Stokke (15) did not report the detection of 4-methylpimelic and 4methylsuberic acids.

Methyl-branched and odd-numbered fatty acids have been identified in the lipids of a patient with methylmalonic acidemia (12). These were believed to arise from the substitution of methylmalonyl-CoA for malonyl-CoA in the reactions catalyzed by fatty acid synthetase. $\omega$-Oxidation of the methyl-branched fatty acids would lead to methyl-branched dicarboxylic acids. However, the methyl-branched dicarboxylic acids identified in this study were more elevated in the amniotic fluid and urine of patients with propionic acidemia than those with methylmalonic acidemia. This excludes methyl-branched fatty acids derived from methylmalonyl-CoA as precursors of the methyl-branched dicarboxylic acids, because patients with propionic acidemia are unable to carboxylate propionyl-CoA to methylmalonyl-CoA.

The possible mechanisms by which the 4-methyl-branched chain dicarboxylic acids are biosynthesized are of interest. 4Methylpimelic acid could result ultimately from the condensation of two molecules of accumulated propionyl-CoA, a reaction which could be catalyzed by 3 -oxothiolase (Fig. 7). The resultant 2-methyl-3-oxovaleryl-CoA is consistent with the fact that 2methyl-3-oxovaleric acid and its hydroxy acid have been identified in propionic acidemia (17). Following reduction, chain elongation with malonyl-CoA could be catalyzed by fatty acid synthetase to yield the 4-methylheptanoyl-CoA ester. This compound would be converted to 4-methylpimelic acid by $\omega$-oxidation and hydrolysis of the CoA ester.

Similarly, condensation of propionyl-CoA with acetyl-CoA catalyzed by 3-oxothiolase would yield 2-methyl-3-oxobutyryl$\mathrm{CoA}$ and chain elongation and $\omega$-oxidation could yield 3-meth-

$$
\begin{aligned}
& \begin{array}{c}
\mathrm{CH}_{3}-\mathrm{CH}_{2}-\mathrm{C}-\mathrm{S}-\mathrm{CoA}+\mathrm{CH}_{3}-\mathrm{CH}_{2}-\mathrm{C}-\mathrm{S} \cdot \mathrm{CoA} \\
\text { Propionyl-CoA } \\
0
\end{array} \\
& \text { 3-Oxothiolase } \\
& \mathrm{CH}_{3} \cdot \mathrm{CH}_{2} \cdot \stackrel{\mathrm{C}}{\mathrm{C}}-\stackrel{\mathrm{C}}{\mathrm{C}} \mathrm{H}-\mathrm{H}_{3}-\mathrm{C} \cdot \mathrm{S} \cdot \mathrm{COA} \\
& \text { 2-Methyl-3-oxovaleryl-CoA } \\
& \downarrow \text { Reduction } \\
& + \text { Dehydration } \\
& + \text { Reduction }
\end{aligned}
$$

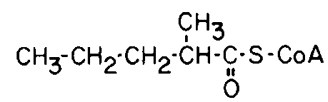

$$
\begin{aligned}
& \text { 2-Methylvaleryl-CoA } \\
& \begin{array}{l|l}
\text { Malonyl-COA } & \begin{array}{l}
\text { Fatty Acid } \\
\text { Synthetase }
\end{array}
\end{array} \\
& \mathrm{CH}_{3} \cdot \mathrm{CH}_{2}-\mathrm{CH}_{2}-\stackrel{\mathrm{C}_{3} \mathrm{H}_{3}}{\mathrm{C}} \cdot \mathrm{C} \cdot \mathrm{CH}_{2} \cdot \mathrm{C}-\mathrm{S}-\mathrm{CoA} \\
& \text { 3.0.0.4-methylheptanoyl-COA } \\
& \downarrow \text { Reduction } \\
& \text { t Dehydration } \\
& \downarrow \text { Reduction }
\end{aligned}
$$

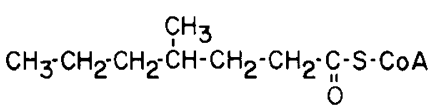

$$
\begin{aligned}
& \text { 4-Methylheptanoyl-CoA } \\
& \begin{array}{l}
\text { Omega Oxidation } \\
\text { Hydrolysis }
\end{array} \\
& \mathrm{CH}_{3} \\
& \mathrm{HOOC}-\mathrm{CH}_{2}-\mathrm{CH}_{2} \cdot \stackrel{\dot{\mathrm{C}}}{\mathrm{H}} \cdot \mathrm{CH}_{2} \cdot \mathrm{CH}_{2} \cdot \mathrm{COOH} \\
& \text { 4-Methylpimelic Acid }
\end{aligned}
$$

Fig. 7. Proposed pathway for the biosynthesis of 4-methylpimelic acid from propionyl-CoA.

yladipic acid. One could speculate that in analogy condensation of propionyl-CoA with butyryl-CoA catalyzed by 3-oxothiolase would yield 2-methyl-3-oxohexanoyl-CoA and chain elongation and $\omega$-oxidation could yield 4-methylsuberic acid. 
Furthermore, additional chain elongation before the $\omega$-oxidation step in the biosynthesis of these methyl-branched chain dicarboxylic acids would be expected to lead to methylazeleic and methylsebacic acids.

Finally, condensation of propionyl-CoA with malonyl-CoA and chain elongation by fatty acid synthetase followed by $\omega-$ oxidation would yield straight chain odd-numbered dicarboxylic acids. The occurrence of $\mathrm{C}_{15}-\mathrm{C}_{17}$ straight chain fatty acids has been reported in hepatic (9) and erythrocyte (7) fat of two patients with propionic acidemia $(7,9)$ and in the glycerolipids of the nervous system of a patient with methylmalonic acidemia (12). These studies on the identification and quantitation of methylbranched and straight chain dicarboxylic acids in amniotic fluid and urine in propionic and methylmalonic acidemia may contribute to explanations of the abnormal biochemistry of these disorders and to better understanding of the mechanisms of clinical illness.

Acknowledgments. We thank Dr. O. W. Jones for providing normal amniotic fluids and the many physicians who sent amniotic fluids from pregnancies at risk for the organic acidurias. We thank Dr. S. G. Kahler and Dr. Mace for providing the urine of the patients with propionic acidemia and methylmalonic acidemia, respectively.

\section{REFERENCES}

1. Allen RJ, Hansch DB, Wu HLC 1982 Hypocarnitinaemia in disorders of organic acid metabolism. Lancet 2:500

2. Buchanan PD, Kahler SG, Sweetman L, Nyhan WL 1980 Pitfalls in the prenatal diagnosis of propionic acidemia. Clin Genet 18:177

3. Chalmers RA, Lawson AM 1982 Organic Acids in Man. Chapman and Hall, London
4. Duran M, Gompertz D, Bruinvis L, Ketting D, Wadman SK 1978 The variability of metabolite excretion in propionic acidemia. Clin Chim Acta $82: 93$

5. Furniss BS, Hannaford AJ, Rogers V, Smith PWG, Tatchell AR (eds) 1978 Vogel's Textbook of Practical Organic Chemistry, ed 4. Longman, London, pp $510-511$

6. Furniss BS, Hannaford AJ, Rogers V, Smith PWG, Tatchell AR (eds) 1978 Vogel's Textbook of Practical Organic Chemistry, ed 4. Longman, London, pp 94-96, 485-488

7. Gompertz D, Bau DCK, Storrs CN, Peters TJ, Huges EA 1970 Localisation of enzymic defect in propionicacidaemia. Lancet $1: 1140$

8. Goodman SI, Markey SP 1981 Diagnosis of Organic Acidemias by Gas Chromatography-Mass Spectrometry. Alan R. Liss Inc, New York

9. Hommes FA, Kuipers JRG, Elema JD, Jansen JF, Jonxis JHP 1968 Propionicacidemia, a new inborn error of metabolism. Pediatr Res 2:519

10. Jakobs C, Sweetman L, Wadman SK, Duran M, Saudubray JM, Nyhan WL 1984 Prenatal diagnosis of glutaric aciduria type II by direct chemical analysis of dicarboxylic acids in amniotic fluid. Eur J Pediatr 141:153

11. Jakobs C 1983 Contribution to the prenatal diagnosis of inherited metabolic disorders: analysis of metabolites in amniotic fluid. Doctoral thesis, Rijksuniversiteit, Utrecht

12. Kishimoto Y, Williams M, Hugo WM, Hignite C, Biemann K 1973 Branchedchain and odd-numbered fatty acids and aldehydes in the nervous system of a patient with deranged vitamin $B_{12}$ metabolism. J Lipid Res 14:69

13. Markey SP, Urban WG, Levine SP (eds) 1974 Mass spectra of compounds of biological interest, vol II, part 1. Atomic Energy Commission, Office of Information Services, Technical Information Center, Oak Ridge, TN

14. Roe CR, Bohan TP $1982 \mathrm{~L}$-Carnitine therapy in propionic acidemia. Lancet $1: 141 \hat{1}$

15. Pettersen JE, Stokke O 1973 Branched short-chain dicarboxylic acids in human urine. Biochim Biophys Acta 304:316

16. Sweetman L, Naylor G, Ladner T, Holm J, Nyhan WL, Hornbeck C, Griffiths J, Morch L, Brandange S, Gruenke L, Craig JC 1982 Prenatal diagnosis of propionic and methylmalonic acidemia by stable isotope dilution analysis of methylcitric and methylmalonic acids in amniotic fluids. In: Schmidt HL Förstel H, Heinzinger K (eds) Stable Isotopes. Elsevier Scientific, Amsterdam

17. Truscott RJW, Pullin C, Halpern B, Hammond J, Haan E, Danks DM 1979 The identification of 3-keto-2-methylvaleric acid and 3-hydroxy-2-methylvaleric acid in a patient with propionic acidemia. Biomed Mass Spectrom $6: 294$

\title{
Glucocorticoids Preferentially Increase Fetal Alveolar $\beta$-Adrenoreceptors: Autoradiographic Evidence
}

\author{
PETER BARNES, ${ }^{1}$ MARK JACOBS, ${ }^{2}$ AND JAMES M. ROBERTS ${ }^{3}$ \\ Department of Obstetrics, Gynecology, and Reproductive Sciences and Cardiovascular Research Institute, \\ University of California, San Francisco, California 94143
}

\begin{abstract}
To localize fetal rabbit lung $\beta$-adrenoreceptors before and after glucocorticoid treatment, light microscopic autoradiography was performed with the reversible radiolabeled $\beta$-adrenergic antagonist, $\left[{ }^{3} \mathrm{H}\right]$ dihydroalpreno-
\end{abstract}

Received April 27, 1983; accepted November 29, 1983.

Reprint requests may be addressed to James M. Roberts, M.D., Department of Obstetrics, Gynecology, and Reproductive Sciences, HSE 1453, University of California, San Francisco, San Francisco, CA 94143

This work was supported by National Institutes of Health Grant HUHD 24056

${ }^{1}$ Current address: Department of Medicine, Royal Postgraduate Medical School, Hammersmith Hospital, London W12 OHS, England.

${ }^{2}$ Recipient of National Institutes of Health Training Grant HD07162. Current address: Department of Obstetrics, Gynecology and Reproductive Sciences, HSE 1462. University of California, San Francisco, San Francisco, CA 94143.

${ }^{3}$ Recipient of National Institutes of Health Career Development Award HD00267. lol, on day 26 of gestation. Autoradiograms of adult lung and fetal myocardium were also prepared. Examination of these autoradiograms showed densely labeled airways, alveoli, and myocardium. Specific labeling, defined as that prevented by incubation with l-propranolol $(1 \mu \mathrm{M})$, was $90 \%$. Analysis of grain counts in the fetus showed that airways were more densely labeled than alveoli $(p<0.001)$, labeling was increased by treatment $(p<0.001)$ and treatment increased alveolar $(p<0.002)$ but not airway labeling. Adult lungs were much more densely labeled than fetal, and fetal myocardial labeling was not altered by treatment. Adult untreated lung showed the same pattern as fetal untreated lung with airways being more densely labeled than alveoli $(p<0.001)$. To validate estimates of 